\title{
A Case of Hepatotoxicity by Salvia Plebeia R. Br.
}

\author{
Chang-gue Son \\ Liver and Immunology Research Center, Oriental Medical College in Dae-Jeon University
}

\section{A Case of Hepatotoxicity by Salvia Plebeia R. Br.}

\author{
Chang-gue Son \\ Liver and Immunology Research Center, Oriental Medical College in Dae-Jeon University
}

\begin{abstract}
Objective: To investigate the possibility of hepatotoxicity by supplemental foods or folk herbs such as Salvia Plebeia R. Br.

Methods: A hospitalized male patient with alcoholic liver disease and electrolyte imbalance had recovered, and then followed by rapid hepatic serum enzymes after taking $S$. Plebeia. This study monitored the clinical outcome and biochemical parameters.

Result: A 58-year male had drunk frequently, which led to alcoholic steatohepatitis and hospitalization. Two weeks after his discharge from hospital, he felt nausea, dizziness, and mild difficulties in speech and walking, resulting in re-hospitalization at the Korean Medical Hospital. The symptoms disappeared on correction of the electrolyte imbalance suspected to have been caused by severe sweating while working in the outdoors, and the patient was discharged. During treatment and monitoring of his health as an outpatient, the serum hepatic enzyme rapidly elevated approximately 10-fold in hepatic enzymes: the enzyme levels fluctuated according to whether or not he was taking the boiled water of $S$. Plebeia. The RUCAM score was 12, which met the criteria for toxic hepatitis by $S$. Plebeia. His general condition and abnormal hepatic enzymes recovered with cessation of $S$. Plebeia and administration of Chungganplus syrup (CGX).
\end{abstract}

Conclusion: This study reports the hepatotoxic risk of Salvia Plebeia, which is commonly used as a folk remedy in Korea.

Key words: Salvia Plebeia, adverse reaction, hepatotoxicity, folk herb

\section{Introduction}

Along with drug-related hepatotoxicity, certain dietary supplements or folk herbs can induce the hepatic injury'. Among drug-induced liver injury (DILI), recently herb-induced liver injury (HILI)

· 투고일: 2019.09.21, 심사일: 2019.12.17, 게재확정일: 2019.12.17

- Corresponding author: Chang-gue Son Liver and Immunology Research Center, Daejeon Oriental Hospital of Daejeon University, Daedukdae-ro 176 bun-gil 75, Seo-gu, Daejeon, Republic of Korea

TELL: +82-42-484-6484 FAX: +82-42-470-9005 E-mail: ckson@dju.ac.kr is getting attention due to the broad adoption of herbs worldwide ${ }^{2}$. One study reported that herbal drugs are responsible for $24.2 \%$ of DILI cases in China ${ }^{3}$.

On the other hand, especially in Korea, there are arguments that HILI has been overestimated and then exaggerated for the risk size of herb related hepatotoxicity ${ }^{4}$. One group reported that herbal drugs attributed $30.7 \%$ of 371 DILI-related hospitalizations in Korea ${ }^{5}$. However, another study presented the $0.5 \%$ proportion of HILI among 567 cases of the adverse drug reaction (ADR) on liver 
from nine regional pharmacovigilance centers ${ }^{6}$.

Korea has a long history traditionally to use the herbs for health and treatment of diseases. This fact has led to that many peoples administrate herbs by themselves without any consults to Korean doctors ${ }^{7}$. Furthermore, even medical doctors frequently don't distinguish folk drugs taken by general subjects themselves from herbal medicines by prescribed by Korean Medicine doctors when they reported the HILI in scientific articles ${ }^{8}$. Recently, there are many concerns about the adverse reactions by functional food supplements in Korea.10.

This case report presents a hepatotoxicity by Salvia Plebeia R. Br., a folk herb, used by many peoples for their respiratory symptoms. This report will inform Korean Medicine doctors and let them have attention the possibility of hepatic injury by folk herb including $S$. Plebeia in clinics.

\section{Report of the case}

\section{Medical history and examination}

A 58-year-old man, an engineer of pokeurein, has been healthy with a little obese body mass index (BMI, 26.2). He has enjoyed the drinking (1 bottle of soju daily) and smoking (1 pack daily), however he had not past or family history of hepatic disease. Recently, the patient experienced $5 \mathrm{~kg}$ of weight loss in 2 months, and felt malaise and anorexia, which led to hospitalization in a Hospital. He was diagnosed with alcoholic hepatic disorder through medical examination including abdominal sonograph and blood tests. The patient stopped both drinking and smoking, and discharged with normal condition after 7-day treatment.

He returned into his general work as an engineer of pokeurein. On 14 day of discharge from the hospital, he visited a Korean Medicine hospital with complaining the moderate level of nausea, dizziness and mild difficulties in speech and walking. He was hospitalized in a Korean Medicine hospital, with a suspected possibility of the electrolyte imbalance, brain infarction or Parkinson disease accompanying with chronic alcoholic liver disorder. From the laboratory tests, the abnormally lowed levels of sodium (112 mol/L, normal range 135-147 $\mathrm{mol} / \mathrm{L}$ ) and chloride $(87 \mathrm{~mol} / \mathrm{L}$, normal range 95-110 mol/L) existed. In addition, slight elevated aspartate aminotransferase (AST, $63 \mathrm{IU} / \mathrm{L}$ ) and total bilirubin $(1.8 \mathrm{mg} / \mathrm{ml})$ as well as the reduced platelet count $\left(6.8 \times 10^{4}\right)$ and serum albumin $(3.0$ $\mathrm{g} / \mathrm{dL}$ ) were found. In particular, his hepatic stiffness measurement (LSM, $35.8 \mathrm{kPa}$ ) showed a range of liver cirrhosis using Fibroscan. Some gas in bowel loops was observed from an $\mathrm{x}$-ray examination for abdomen (Fig. 1).

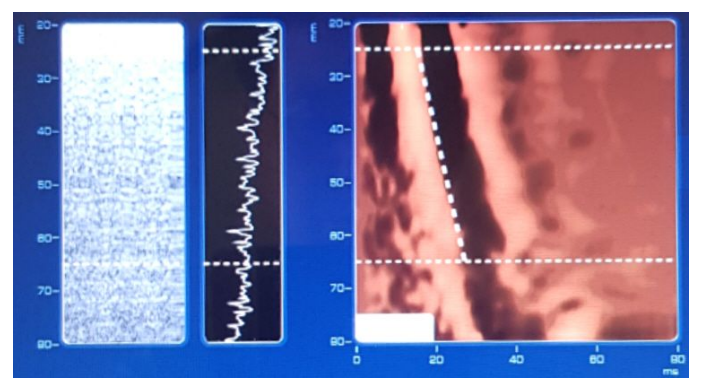

Fig. 1. Fibroscan measurement.

The cirrhotic change was observed in Fibroscan.

\section{Treatment and occurrence of hepatotoxicity}

In order to correct the electrolyte imbalance, intravenous therapy was given to the patient, while an herbal medicine, Chungganplus syrup (CGX, two packs per day) was also prescribed for care hepatic disorder. His main symptoms such a s nausea, dizziness, and lagging speech and walking 
began to improve quickly during those treatments. Thus, the patient discharged after five-day hospitalization, and laboratory tests including electrolytes were normal range except a mild reduction of platelet count $\left(10.3 \times 10^{4} / \mu \mathrm{l}\right)$.

When the patient visited my clinic department on 10 days later of discharge-hospital, as an outpatient, his chemistry test showed the abnormal elevation of AST up to 259 IU/L. This unexpected finding led me to recheck the hepatic enzymes which presented an acute severe hepatic injury, AST 546 U/L, ALT 330 U/L, ALP 198 U/L, and GGT 86 U/L, respectively. From the interview, $S$. Plebeia was suspected as the cause, which the patient drunk it (as boiled water) for his respiratory symptoms, coughing and mild sputum. After stopping the administration of $S$. Plebeia, the elevated hepatic enzymes were rapidly decreased by half-levels, and then those enzymes jumped up again in one week later. It was noticed that the patient re-administrated with S. Plebeia. In fact, the patient didn't believe the possibility of hepatotoxicity by $S$. Plebeia, thus he retried to take $S$. Plebeia. The hepatic enzymes became almost normalized since the patient quit the drinking of $S$. Plebeia-boiling water for 2 weeks (Fig. 2).

During the hepatic injury happening, the patient didn't feel any subjective discomfort symptom including fatigue or indigestion. The RUCAM score was 12 , which met the criteria for toxic hepatitis by $S$. Plebeia. As same as inpatient treatments, only CGX had been prescribed for the patient.

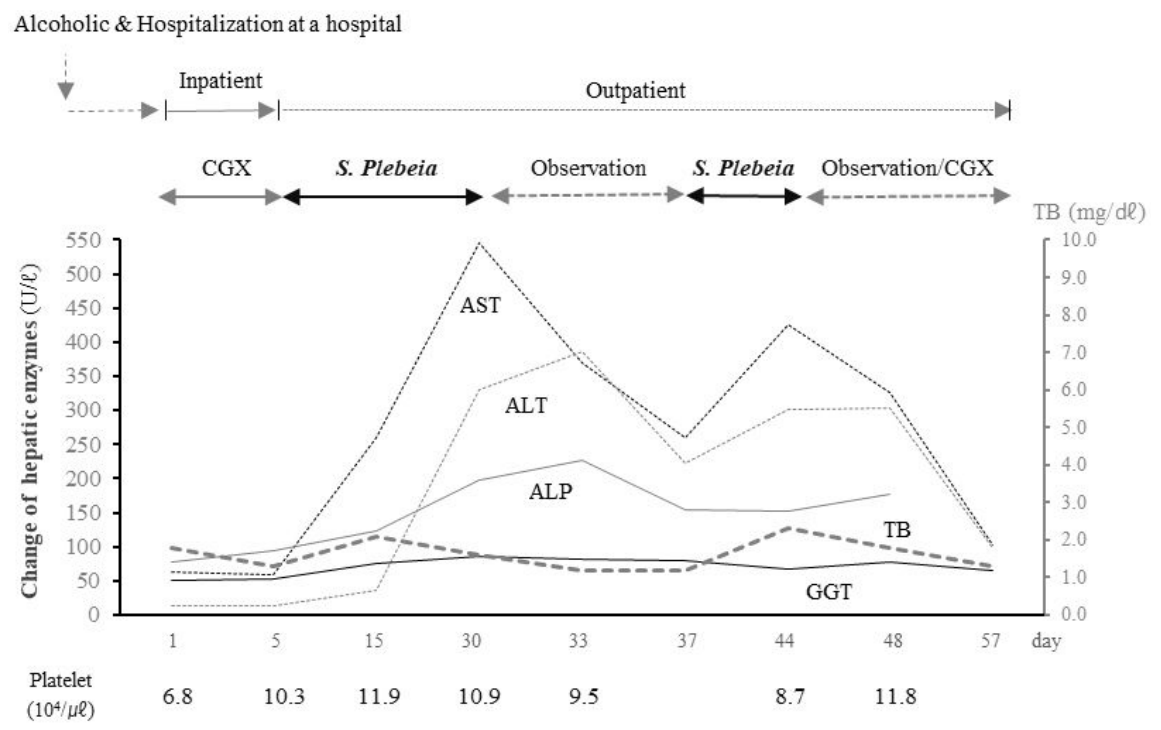

Fig. 2. Summary of clinical course.

Clinical events and findings from blood tests were presented. CGX : Chungganplus syrup, AST : aspartate aminotransferase, ALT : alanine aminotransferase, ALP : alkaline phosphatase, TB: total bilirubin. 


\section{Discussion and Conclusion}

Salvia Plebeia R. Br. is widely distributed in many countries, especially in Asia. This plant has been used as a folk herb for the treatment of cough, inflammation and haemorrhoids ${ }^{11}$. Recent researches reported its biological activities such as antioxidant, antimicrobial and even hepatoprotective activities $^{12-14}$. One group conducted a toxicological study of $S$. Plebeia mixed with red ginseng (ratio $3: 1$ as $30 \%$ ethanol extract) using 4 -week oral administration in rats. This study demonstrated the safety of $S$. Plebeia as over $2,000 \mathrm{mg} / \mathrm{kg}$ bw/day of no-observed-adverse-effect level (NOAEL) ${ }^{15}$.

S. Plebeia is an edible plant, which can be taken by general population without any warning. However, the common materials known as safe can induce hepatic injury to certain subjects under certain conditions. In this case, although his hepatic inflammation was sedative on time point of admission, the patient has a reduced hepatic function due to cirrhotic change evidenced by LSM measurement, which was supported by reversed AST / ALT ratio (68 and $13 \mathrm{U} / \mathrm{L},>3$ ) and the reduced platelet count and serum albumin. This cirrhotic condition might increase the hepatic susceptibility against $S$. Plebeia as well as risk for the disturbance of electrolytes. The cirrhotic change indicates the notable impairment of hepatic capacity for drug metabolism ${ }^{16}$. Regarding the causality assessment, Roussel Uclaf Causality Assessment Method (RUCAM), an algorithm to measure the strength of association between hepatic injury and suspected agent, is commonly used. RUCAM score is considered as highly probable (>8), probable (6-8) or possible $(3-5)$, and scores $\leq 3$ were not included in HILI. Then, the score of this case was 12 as follows: 2 from "Time to onset-5 to 90 days", 3 from "Course-decrease $\geq 50 \%$ within 8 days", 2 from "Risk factor-alcohol and age $\geq 55$ years", 2 from "Exclusion of others causes" and 3 from "Response to re-administration" respectively.

In fact, there is the case report for serious liver and kidney damage due to the misuse of $S$. Plebeia ${ }^{17}$. The development of adverse reaction to drugs or food materials is decided by three factors; drug/food property itself, genetic background of individual and environmental factors including underlying disorders, concomitant drug, alcohol use, gender or age ${ }^{18}$. Hepatotoxicity is the most serious form of ADR or food-related adverse reaction. This case would belong to idiosyncratic metabolic responses that show the dose independent and unpredictable patterns ${ }^{19}$. The types of liver injury can be classified as hepatocellular $(R \geq 5)$, cholestatic $(R \leq 2)$, or mixed $(2<R<5)$, based on the ratio of serum ALT to ALP designated as the $R$ value $\left([\text { ALT value/ALT UNL]/[ALP value/ALP UNL] })^{20}\right.$. Comparing to ALP and total bilirubin, both AST and ALT were remarkably elevated, and the R value was 5.4, which indicated the hepatocellular injury type. Contrast to Western drug-related hepatotoxicity, the portion of hepatocellular injury type is known to generally be predominant in HILI comparing to other types ${ }^{21}$. One study showed the similar clinical outcomes among three types of hepatic injuries ${ }^{22}$, while others presented the poor outcomes and higher mortality in patients with hepatocellular type of $\mathrm{DILI}^{23}$.

The principle of management for drug/food-related hepatic injury is to stop early the use of suspected agents. The vast majority of cases of DILI recover fully clinically and biochemically, however patients meet the criteria for Hy's law, defined as 
either AST or $\mathrm{ALT} \geq 3 \times \mathrm{UNL}$ and $\mathrm{TB} \geq 2 \times \mathrm{UNL}$ without evidence of cholestasis ( $\mathrm{ALP} \leq 2 \times \mathrm{UNL}$ ), shows the approximately $10 \%$ of mortality ${ }^{24}$. The patient of this case was not meet the criteria for Hy's law. He had showed the recurrence after the re-administration with $S$. Plebeia again because he didn't accept the cause of S. Plebeia. However, the patient confirmed the no used of alcohol during of outpatient. He has been prescribed CGX and recovered finally laboratory tests near to normal range. CGX is $10 \mathrm{ml}$ syrup containing $2 \mathrm{~g}$ extract from 13 herbs, and its detail composition has been described in previous report ${ }^{25}$. CGX has been used for both acute and chronic liver disorders including DILI based on its hepatoprotective effects ${ }^{26.27}$.

This case report presented S. Plebeia-induced hepatotoxicity. S. Plebeia has been commonly used as a fork remedy in Korea, thus Korean doctors need to be aware of it in clinical field.

\section{References}

1. de Boer YS, Sherker AH. Herbal and Dietary Supplement-Induced Liver Injury. Clin Liver Dis 2017;21(1) :135-49.

2. García-Cortés M, Robles-Díaz M, Ortega-Alonso A, Medina-Caliz I, Andrade RJ. Hepatotoxicity by Dietary Supplements: A Tabular Listing and Clinical Characteristics. Int $J \mathrm{Mol} S \mathrm{Sc}$ 2016;17(4):537.

3. Li B, Wang Z, Fang JJ. Evaluation of prognostic markers in severe drug-induced liver disease. World J Gastroenterol 2007;13(4):628-32.

4. Cho JH, Oh DS, Hong SH, Ko H, Lee NH, Park SE, et al. A nationwide study of the incidence rate of herb-induced liver injury in Korea. Arch Toxicol 2017:91(12):4009-15.
5. Suk KT, Kim DJ, Kim CH, Park SH, Yoon $\mathrm{JH}$, Kim YS, et al. A prospective nationwide study of drug-induced liver injury in Korea. Am J Gastroenterol 2012;107(9):1380-7.

6. Kwon H, Lee SH, Kim SE, Lee JH, Jee YK, Kang HR, et al. Spontaneously reported hepatic adverse drug events in Korea: multicenter study. J Korean Med Sci 2012;27(3) :268-73.

7. Kim JH, Cho JH, Son CG. A Case Report for a Toxic Liver Injury Caused by Voluntary Administration of Smilacis Chinae Radix. Korean $J$ Orient Int Med 2012;33(4):609-14.

8. Park HM, Jang IS, Lee SD. Hepatotoxic Events Associated with Herbal Medicinal Products, Folk Remedies and Food Supplements in Korea. $J$ Korean Orient Med 2005;26(2):152-65.

9. Lee WJ, Kim HW, Lee HY, Son CG. Systematic review on herb-induced liver injury in Korea. Food Chem Toxicol 2015;84:47-54.

10. Shin JY, Choi NK, Park BJ, Jung SY, Lee JH, Kim YJ, et al. Patterns of Suspected Adverse Events with Health Functional Foods and Diversity of Reported Terms. $J$ Pharmacoepidem Risk Manag 2009:2(1):45-51.

11. Jin XF, Lu YH, Wei DZ, Wang ZT. Chemical fingerprint and quantitative analysis of Salvia plebeia R.Br. by high-performance liquid chromatography. J Pharm Biomed Anal 2008; 48(1) :100-4.

12. Weng XC, Wang W. Antioxidant activity of compounds isolated from Salvia plebeia. Food Chem 2000;71(4) :489-93.

13. Baek SW, Shin MK, Kim SK, Lee SK, Kang YS, Kim SS, et al. Cytotoxicity and antimicrobial effect of the extract of Salvia plebeia. Kor $J$ Pharmacogn 2001;32(1):55-60.

14. Jin XF, Qian J, Lu YH. The role of hepatoprotective 
effect of a flavonoid-rich extract of Salvia plebeia R. Br. on carbon tetrachloride-induced acute hepatic injury in mice. $J$ Med Plants Res 2011:5(9) :1558-63.

15. Seo HW, Suh JH, Kyung JS, Jang KH, So SH. Subacute Oral Toxicity and Bacterial Mutagenicity Study of a Mixture of Korean Red Ginseng (Panax ginseng C.A. Meyer) and Salvia plebeia R. Br. Extracts. Toxicol Res 2019:35(3) :215-24.

16. Dietrich CG, Götze 0, Geier A. Molecular changes in hepatic metabolism and transport in cirrhosis and their functional importance. World $J$ Gastroenterol 2016;22(1):72-88.

17. Yang X, Chen D, Chai L, Duan H, Guo H, Li S, et al. A Case Report of Poisoning Caused by Incorrect Use of Salvia. Am $J$ Case Rep 2016;17:580-3.

18. Khoury T, Rmeileh AA, Yosha L, Benson AA, Daher S, Mizrahi M. Drug Induced Liver Injury: Review with a Focus on Genetic Factors, Tissue Diagnosis, and Treatment Options. $J$ Clin Transl Hepatol 2015:3(2):99-108.

19. Au JS, Navarro VJ, Rossi S. Review article: Drug-induced liver injury its pathophysiology and evolving diagnostic tools. Aliment Pharmacol Ther 2011:34(1) :11-20.

20. Madariaga MG. Drug-related hepatotoxicity. $N$
Engl J Med 2006;354(20):2191-3.

21. Byeon JH, Kil JH, Ahn YC, Son CG. Systematic review of published data on herb induced liver injury. J Ethnopharmacol 2019:233:190-6.

22. Lu RJ, Zhang Y, Tang FL, Zheng ZW, Fan ZD, Zhu SM, et al. Clinical characteristics of drug-induced liver injury and related risk factors. Exp Ther Med 2016;12(4):2606-16.

23. Chalasani N, Bonkovsky HL, Fontana R, Lee W, Stolz A, Talwalkar J, et al. Features and Outcomes of 899 Patients with Drug-Induced Liver Injury: The DILIN Prospective Study. Gastroenterology 2015 Jun;148(7) :1340-52.

24. Regev A, Björnsson ES. Drug-induced liver injury: morbidity, mortality, and Hy's law. Gastroenterology 2014;147(1):20-4.

25. Wang JH, Shin JW, Son JY, Cho JH, Son CG. Antifibrotic effects of CGX, a traditional herbal formula, and its mechanisms in rats. $J$ Ethnopharmacol 2010;127(2):534-42.

26. Hu XP, Shin JW, Wang JH, Cho JH, Son JY, Cho CK, et al. Antioxidative and hepatoprotective effect of CGX, an herbal medicine, against toxic acute injury in mice. $J$ Ethnopharmacol 2008; $120(1): 51-5$.

27. Son CG. A Severe Hepatotoxicity by Antituberculosis Drug, and its Recovery in Oriental Hospital. $J$ Korean Med 2016:37(2):119-24. 